Document downloaded from:

http://hdl.handle.net/10251/50609

This paper must be cited as:

Rnaudo, P.; Torres Górriz, B.; Paya-Zaforteza, I.; Calderón García, PA.; Sales Maicas, S. (2015). Evaluation of new regenerated fiber Bragg grating high-temperature sensors in an ISO 834 fire test. Fire Safety Journal. 71:332-339. doi:10.1016/j.firesaf.2014.11.024.

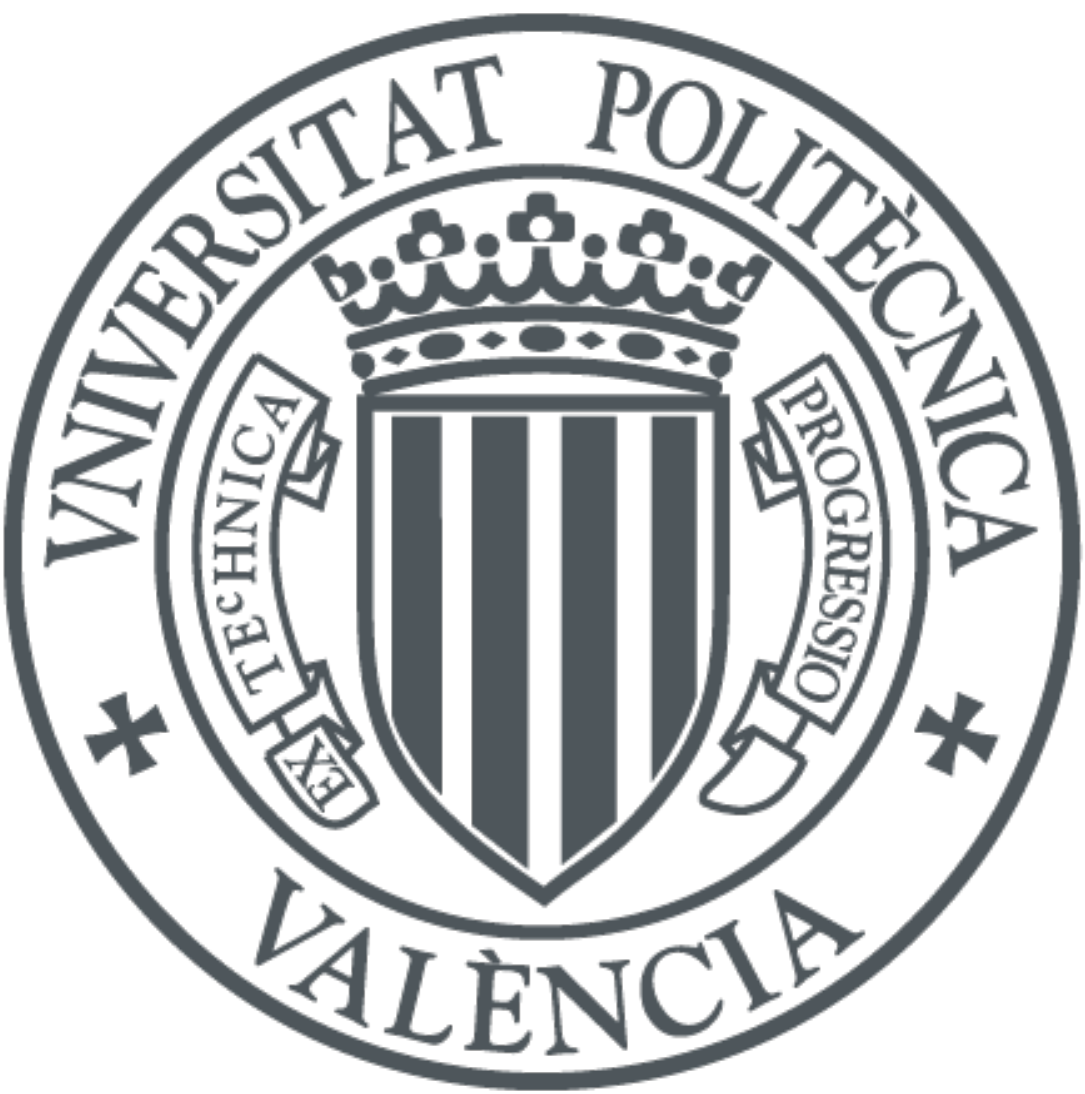

The final publication is available at

http://dx.doi.org/10.1016/j.firesaf.2014.11.024

Copyright Elsevier

Additional Information 
Please, cite this paper as:

Rinaudo, P., Torres, B., Paya-Zaforteza, I., Calderón, P.A., Sales, S.

Evaluation of new regenerated fiber Bragg grating high-temperature sensors in an ISO

834 fire test

(2015) Fire Safety Journal, 71, pp. 332-339.

DOI: 10.1016/j.firesaf.2014.11.024 
Please, cite this paper as:

Rinaudo, P., Torres, B., Paya-Zaforteza, I., Calderón, P.A., Sales, S.

Evaluation of new regenerated fiber Bragg grating high-temperature sensors in an ISO 834 fire test

(2015) Fire Safety Journal, 71, pp. 332-339.

DOI: 10.1016/j.firesaf.2014.11.024

\title{
Evaluation of New Regenerated Fiber Bragg Grating High-Temperature Sensors in an ISO 834 Fire Test
}

\author{
Paula Rinaudo ${ }^{1}$, Benjamín Torres ${ }^{1}$, Ignacio Paya-Zaforteza ${ }^{1 *}$, Pedro A. Calderón, Salvador Sales ${ }^{2}$ \\ ${ }^{I}$ ICITECH, Departamento de Ingeniería de la Construcción y Proyectos de Ingeniería Civil, Universitat Politècnica de \\ València, Camino de Vera s/n, 46022, Valencia, Spain. \\ ${ }_{2}^{2}$ ITEAM, Departamento de Comunicaciones, Universitat Politècnica de València, Camino de Vera s/n, 46022, Valencia, \\ Spain.
}

$\begin{array}{lll}\text { Authors e-mail addresses: } & \text { Paula Rinaudo: } & \text { pauri@posgrado.upv.es } \\ & \text { Benjamín Torres: } & \text { bentorgo@upv.es } \\ & \text { Ignacio Paya-Zaforteza: } & \text { igpaza@cst.upv.es } \\ & \text { Pedro A. Calderon: } & \text { pcaldero@cst.upv.es } \\ & \text { Salvador Sales Maicas: } & \text { ssales@dcom.upv.es }\end{array}$

\begin{abstract}
:
Temperature, one of the most important parameters in building fires, is now mostly measured with hightemperature thermocouples, which have the typical drawbacks of electric sensors, such as their sensitivity to electrical and magnetic interference. Fiber optic sensors are an alternative to electric sensors and offer many advantages, although their use in fire engineering is somewhat limited at the present time. This paper presents a set of new fiber optic sensors for measuring high temperatures, based on Regenerated Fiber Bragg Gratings (RFBGs). The sensors were placed near the surface of two concrete specimens and then tested under ISO 834 fire curve conditions for one hour. We consider this an important step forward in the application of hightemperature fiber optic sensors in fire engineering, as the sensors were subjected to direct flames and temperature increments of the order of $200{ }^{\circ} \mathrm{C} / \mathrm{min}$, similar to those in a real fire. The FBG sensors measured maximum gas temperatures of circa $970{ }^{\circ} \mathrm{C}$, in good agreement with those provided by thermocouples in the same position. The gas temperature measurements of the FOSs were also compared with the adiabatic temperatures measured by plate thermometers and concrete specimens surface temperatures calculated with numerical heat transfer models.
\end{abstract}

Keywords: Fire; high temperature measurement; fiber optic sensor; regenerated fiber bragg grating; ISO 834.

* Corresponding author. Tel: +34 963877562; fax: +34 963877568 


\section{Introduction}

Reports and publications [1-3] issued after disasters such as the fires in the Tauern tunnel (2001), the Windsor Building in Madrid (2005) or the Beijing Television Cultural Center (2008) show the importance of installing strain and/or temperature sensors in structures vulnerable to fires as these sensors can be very helpful to estimate the maximum temperature reached by a structure as well as to evaluate its damage and residual strength.

Temperature measurement has traditionally been performed by thermocouples, but these are electric sensors and suffer drawbacks such as radiation errors [4]. They also need to be connected individually to the data recording system [5] and are sensitive to electrical and magnetic interference (EMI), which limits their application in different fields such as structural safety or power plants. Fiber optic sensors overcome most of the drawbacks of thermocouples, for example they are immune to EMI and can be multiplexed along a single optical fiber, which means cheaper and simpler monitoring systems that are easy to implement.

In recent years several high temperature fiber optic sensors have been developed using different technologies such as chiral fiber gratings that were tested up to $1000{ }^{\circ} \mathrm{C}$ [6], sapphire gratings which measured maximum temperatures of $1745^{\circ} \mathrm{C}[7]$ and multilayer metal-coated regenerated grating sensors that were calibrated for maximum temperatures of $600{ }^{\circ} \mathrm{C}$ [8]. However, all of these were tested in laboratory electric furnace tests and in conditions very different to those of real fire scenarios or to those of the standard tests used in fire engineering.

Despite their clear advantages, fiber optic sensors (FOS) are thus not greatly used in fire engineering. Lönnermark et al. [9] presented the first application of fiber optic temperature sensors to measure gas temperatures up to $250{ }^{\circ} \mathrm{C}$ in a fire test on a scale model of a tunnel. Another pioneering work was done by Bueno et al. [10], who measured temperatures up to $600^{\circ} \mathrm{C}$ with Fiber Bragg Grating (FBG) sensors and regenerated FBG (RFBG) sensors embedded in concrete specimens. These applications proved the viability of using FBG and RFBG sensors for temperature measurement during fire scenarios but showed the need for further research on fiber optic high temperature sensors to extend their temperature range and to evaluate their behavior under harsh sooty environments. In fact, the need to improve temperature measurement in fires was one of the key conclusions of a recent literature review on measurement of temperature, displacement and strain in structural components submitted to fire loads by McAllister et al. [5].

Within this general context, this paper presents a set of regenerated fiber optic temperature sensors developed by the authors and tested under ISO-834 fire curve [11] flame conditions. Sensors with different packaging systems were installed to measure gas temperature near the surface of two concrete specimens and submitted to ISO-834 conditions for one hour. The main goal of the fire test was to compare the temperatures recorded by the developed fiber optic sensors with those from thermocouples. Additionally, the measurements were compared to the adiabatic temperatures registered by plate thermometers form the furnace and concrete specimens surface temperature predictions obtained with a numerical thermal model of the experiment carried out with the software Abaqus [12].

The results show that RFBG sensors were able to adequately measure temperatures and therefore are suitable for use in fire engineering research and applications. We consider these tests to be important since: (a) they enable the response of the sensor to direct flames to be evaluated in conditions similar to those of real fires; (b) they can detect possible problems associated with the installation of sensing systems similar to those found in monitoring actual building fires; and (c) the fire curves commonly used in fire engineering have extremely fast temperature increments, which were not considered in the tests conducted in electric furnaces reported in [6-8]. 


\section{Description of the fiber optic sensors}

Optical fibers consist of at least two layers of different dielectric materials: core and cladding. The core has a very small diameter and is surrounded by the cladding. Light is only propagated inside the core, as it has a higher refraction index. The cladding is often protected by outer coatings or jackets that provide the fiber with mechanical strength and protect it from damage and moisture absorption[13]. There are several FOS technologies (Fabry-Pérot, Fiber Bragg Gratings and distributed sensing) but Fiber Bragg Grating (FBG) technology is the most widely used in optical sensors today[14]. A development of FBG technology, known as Regenerated Fiber Bragg Grating (RFBG), was used by the present authors to develop their sensors. Both FBG and RFBG technologies are briefly described in the following subsections. Further information can be found at [13-18].

\subsection{Basics of the Fiber Bragg Grating (FBG) and Regenerated Fiber Bragg Grating temperature sensors}

A Fiber Bragg Grating is a periodic or quasi-periodic alteration of the refraction index of the optical fiber core along a length of the optical fiber called grating length. As a consequence, as explained in Figure 1, part of the incident light that is injected into the FBG is transmitted and part is reflected at a specific wavelength, called the Bragg wavelength $\left(\lambda_{B}\right)$. The reflected wavelength is defined by the relationship:

$$
\Delta \lambda_{B}=2 . n_{e f f} \cdot \Lambda
$$

Where $n_{\text {eff }}$ is the effective refractive index of the grating in the fiber core and $\Lambda$ is the grating period [14]. Changes in the strain and/or temperature of a FBG generate a change in its grating period and result in a shift of the Bragg wavelength. In order to develop a sensor that measures temperature only, it is therefore necessary to isolate the optical fiber from any source of mechanical deformation, so that the shift in the Bragg wavelength can be expressed as a function of temperature variations and vice versa. This relationship is defined by a polynomial equation whose coefficients are specific to each sensor and must be obtained experimentally.

Standard FBGs experience problems when submitted to high temperatures as they lose stability and degrade significantly at temperatures close to $600{ }^{\circ} \mathrm{C}[15,16]$. In fact, the Bragg gratings in the sensor are completely erased after the fiber reaches temperatures higher than $600{ }^{\circ} \mathrm{C}$, which makes the sensor useless. One way to overcome this temperature limit is to use Regenerated Fiber Bragg Gratings (RFBGs) [17, 18], which undergo physical and chemical processes that make them stable at high temperatures. RFBGs are created in three steps. First, the fiber is placed in a hydrogenation chamber at room temperature. Then the FBG is inscribed into the hydrogen-loaded optical fiber by laser. Finally, the fibers are subjected to an annealing process inside a tubular furnace. During this phase, as the temperature increases, the original FBGs are progressively degraded until full erasure and a new regenerated FBG (RFBG) is created. As a consequence of their production process, RFBGs are extremely fragile and cannot be installed unprotected in a structural element because both the environmental and mechanical external conditions would affect their durability and behavior. They are therefore protected by packaging, this being a crucial element of the sensor.

\subsection{Description of the high temperature sensors}

The sensors developed by the authors and tested in this work had three different packaging materials: two were metallic (henceforth Materials A and C) and one ceramic (Material B). The sensors were placed near the surface of two concrete specimens and fixed to them. RFBG grating length was $0.5 \mathrm{~cm}$ and a wide range of Bragg wavelengths $\left(\lambda_{0}\right)$ was employed to facilitate interpretation of the data acquired by the sensors during the test. Information on the six sensors tested (FOS1 to FOS6) is given in Table 1 and includes: the specimen on 
which the sensor was placed, packaging material, and the Bragg wavelength reflected by the sensor at the beginning of the test.

Note that different packaging materials were used to make sensors with different properties (maximum measurable temperatures, time the sensors can be exposed to the maximum temperatures, mechanical stiffness, cost and fragility) and therefore with different potential applications. Due to the rigidity and fragility of Material B (ceramics), the length of the packaging was limited to $12 \mathrm{~cm}$. Material C packaging was $16 \mathrm{~cm}$ long, which facilitated its production and manipulation. Further details of the sensors and their development can be found in [19].

\section{Testing of the sensors in a fire test}

\subsection{Experimental setup}

Fiber optic sensors were installed close to the surface of two concrete specimens that measured $0.50 \mathrm{x} 0.10 \mathrm{x} 0.1$ $\mathrm{m}$ and were made of high resistance concrete with steel fibers. Sensors were installed according to the same pattern: the distance of the sensors to the furnace walls was $30 \mathrm{~cm}$, all the sensors were centered on shorter side of the specimens and the distance between the top surface of each specimen and the sensors was approximately $2 \mathrm{~mm}$. This vertical distance of $2 \mathrm{~mm}$ was chosen to place the sensors outside of the gas boundary layer, being this layer, the depth of fluid in the immediate vicinity of the specimens surface where the effects of viscosity are significant and temperatures gradients take place; due to this gradient, gas temperatures within the boundary layer are smaller than outside the boundary layer.

A metallic composite adhesive which keeps its bonding properties up to $1093^{\circ} \mathrm{C}$ was used to fix the sensors and also served to provide small clearance between the sensing component of the sensor and the surface of the specimen (see Figure 2).This decision was taken to avoid errors, as it is difficult to guarantee perfect contact of sensor and concrete surface throughout the entire test. Moreover, we consider more interesting to measure gas temperature than surface temperatures because: (a) gas temperatures give an idea of the size of the fire and concrete surface temperatures can be easily calculated using gas temperatures as boundary conditions, and (b) estimating gas temperatures from concrete surface temperatures would involve a complex iterative analyses. Finally, it must be noted that two Type-k thermocouples measuring $2 \times 0.8 \mathrm{~mm}$ with isolated ceramic fiber cable were used to verify the behavior of the fiber optic sensors. These thermocouples, which are named TC1 and TC2 henceforth, were attached to the specimens with the same adhesive as the high temperature sensors and can be seen in Figure 2.

The sensors under study and the two concrete specimens were subjected to a fire test in which the ISO-834 standard fire curve was applied for one hour. We believe this to be the first time sensors have been subjected to such rigorous testing, as previous work with fiber optic sensors for measuring gas temperatures under fire conditions [9] had tested sensors under more favorable conditions: gas temperatures below $300{ }^{\circ} \mathrm{C}$ and smaller temperature increments. Figure 3 compares the temperatures of the ISO-834 curve with the gas temperature curve used by Lönnermark et al.[9] and it can be seen that the ISO-834 fire curve conditions are much more severe.

The furnace used on the test is cubic in shape with $1.5 \mathrm{~m}$ long sides, with six gas burners distributed along two parallel sides of the chamber. Figure 4 shows the concrete specimens in the furnace previous to the fire test. Concrete specimens were placed on aerated concrete blocks: (a) to facilitate sensor installation and (b) to reduce temperature variations throughout the specimens, since the furnace temperature is more uniform at mid height.

Temperature in the furnace is controlled by four plate thermometers located inside the furnace chamber. The plate thermometers were enumerated from left to right and from back to front. They are named PT1 to PT4 henceforth. PTs were installed with their insulated face facing the specimen. By doing so, the exposed face 
of the PTs received the same radiant heat flux as the specimen and the PTs were not be affected by the radiation of the specimen itself. Plate thermometers are devices that receive a radiant heat flux similar to the test specimens [20] and consequently the temperature measured by them, also called adiabatic temperature, is very appropriate for analyzing heat transfer phenomena in structural elements submitted to fires.

The fiber optic monitoring system had beside of the sensors three additional components: a reading unit, a cable network, and a data management system. The reading unit, also called the interrogator, provides light for the fiber optic sensors, receives the reflected light from the sensors and decodes and transfers information to the data acquisition system (a portable PC). The optical sensing interrogator used (a Micron Optics sm125500) has a wavelength range of 1510-1590 nm and four optical channels. As six channels (one for each sensor) were needed, a multiplexer Micron Optics sm041-416 was used to expand the number of channels from the interrogator. Micron Optics Enlight sensing analysis software [21] was used for data acquisition definition and visualization. Reflected spectrum responses and Bragg wavelengths were recorded every 4 seconds. The third order polynomial relationship given by Eq.(2) was used to transform the Bragg wavelengths measured by the data management system into temperatures.

$\mathrm{T}(\lambda)=\mathrm{a} \lambda^{3}+\mathrm{b} \lambda^{2}+\mathrm{c} \lambda+\mathrm{d}$

The coefficients $a, b, c$ and $d$ in Eq. 2 were calibrated experimentally for each sensor type using a Carbolite MTF 12/38/40 furnace. This furnace guaranteed a uniform distribution of temperatures along the central portion of the furnace, where the optic sensor and a thermocouple were located. Temperatures were increased in different steps from $10{ }^{\circ} \mathrm{C}$ to $1000{ }^{\circ} \mathrm{C}$ for sensor type $\mathrm{A}$ and up to $1100{ }^{\circ} \mathrm{C}$ for sensor types $\mathrm{B}$ and $\mathrm{C}$. At each temperature step, temperatures measured by thermocouples and Bragg wavelengths measured by the optic sensor were recorded. These data where plotted in a graphic and then the Least Squares Method was used to find a mathematical relationship expressing temperatures as a function of Bragg wavelengths (Eq. 2). The correlation coefficient was $\mathrm{R}^{2}=0.9998$ for sensor Type A and 0.9999 for sensor types B and C. It is important to highlight that the coefficients $\mathrm{a}, \mathrm{b}$, and $\mathrm{d}$ depend on the initial wavelength $\lambda_{0}$ of the sensor. For example, for a $\lambda_{0}$ value equal to 1557.255 the values of the coefficients are: $a=5.639 \times 10^{-2} ; b=-265.6 ; c=417,093.445 ; d=$ $-218,335,848$. Those values are valid for a wavelength $\lambda$ expressed in nanometers and a temperature $T$ expressed in Celsius degrees. Detailed information about the calibration process can be found in [19].

\subsection{Numerical model of the test}

A nonlinear heat transfer analysis model to obtain the theoretical surface temperatures on both concrete specimens was developed with Abaqus software [12]. The model had a prismatic part of 10x10x50 cm (see Figure 5) that was meshed with type DC3D8 heat transfer elements, which are three dimensional eight-node linear heat transfer solid elements with one degree of freedom per node. The maximum element size was $1 \mathrm{~cm}$. The FE model had 6171 nodes and 5000 solid elements. Concrete thermal properties and density were defined as temperature-dependent according to Eurocode 2, Part 1-2 [22] and considering that calcareous aggregates were used to make the concrete.

Thermal loads were applied in two steps. The first step defined an initial temperature condition of the specimen. A value of $12{ }^{\circ} \mathrm{C}$ was defined in agreement with the temperature measured by the plate thermometers at the beginning of the test. On the second step the temperatures measured by the plate thermometers were applied as thermal loads. To do so, surface film condition and surface radiation interactions were applied to the four exposed surfaces of the concrete specimens. The convective heat transfer coefficient was defined as $25 \mathrm{~W} /\left(\mathrm{m}^{2} \mathrm{~K}\right)$, the emissivity of the exposed surface was defined as 0.8 and the 
emissivity of the fire as 1 . Stephan Bolzmann constant is $5.67 \times 10-8 \mathrm{~W} / \mathrm{m}^{2} \mathrm{~K}^{4}$. These parameters of the heat transfer problem were defined according to Eurocode 1, Part 1-2 [23].

A different temperature curve was applied to each concrete specimen in the FEM defined by the temperature measured by the plate thermometer nearest to each specimen (PT2 for Specimen 1 and PT3 for Specimen 2). Plate thermometer temperature-time curves are shown in Figure 6.

\section{Results and discussion}

Figure 6 shows the adiabatic surface temperatures inside the furnace measured by the plate thermometers as well as the ISO 834 fire curve. The measurements are not identical as they are influenced by the distance of the thermometers from the burners, but the temperature-time curves were reasonably close to the predefined heating curve, PT4 presenting the largest divergences. A reduction of the temperature in all the curves is shown around 2600 seconds after the beginning of the test, when the pressure inside the furnace became stable.

Figure $7 \mathrm{a}$ and $7 \mathrm{~b}$ show the gas temperatures measured by the sensors on Specimen 1 (FOS1, 3 and 5 and thermocouple TC1) as well as the adiabatic temperatures measurements of the plate thermometer near the specimen (PT2). It also plots the theoretical temperature on the surface of Specimen 1 obtained by the FE model of the experiment (curve FEM1). Figure 8 shows Specimen 1 with its sensors at the end of the test. The results show that:

- FOS1 and TC1 gave very similar measurements. The maximum temperatures measured by FOS1 and $\mathrm{TC} 1$ were $968{ }^{\circ} \mathrm{C}$ and $952^{\circ} \mathrm{C}$, respectively, which represents a difference of $1.65 \%$ of the maximum temperature measured by $\mathrm{TC} 1$.

- There were some discrepancies in sensor measurements at the beginning of the test (see Figure 7b), which can be attributed to small variations in the sensors' vertical positions and consequently variations in their relative position to the gas boundary layer. Figures $7 \mathrm{a}$ and $7 \mathrm{~b}$ also show that FOS measurements have peaks and valleys, especially during the first 300 s of the test, which can be attributed to the short FOS response time and were not due to any sensor noise. The response time indicates the time the sensor takes to react to temperature variations; the shorter the response time the faster the sensor registers temperature variations.

- 740 seconds after the beginning of the test, the sensors showed a fast rise in temperature due to the set defined by the sensor and adhesive becoming detached from the concrete by concrete spalling, as can be seen in Figure 8. This temperature increase actually shows that the thickness of the gas boundary layer was bigger than $2 \mathrm{~mm}$ and that concrete spalling brought the sensors to a final position outside the gas boundary layer.

- FOS3 and 5 broke down after circa 1000s. It should be noted that they both stopped working at the same time, which indicates a global failure and not a local sensor breakdown. After an inspection at the end of the test, it seems that concrete spalling broke the connections between FOS3 and FOS5 and the optical fibers connecting the sensors to the data acquisition system.

- The variation of the furnace temperature around 2600 seconds after the beginning of the test was properly registered by the different FOS, as shown in Figure 7a.

Figure 7c and 7d plot the gas temperatures measured by the sensors on Specimen 2 (FOS2, 4 and 6 and thermocouple TC2), the adiabatic temperatures measurements of the plate thermometer near the specimen (PT3) and the temperatures on the surface of Specimen 2 obtained with the FE model (curve FEM2). Figure 9 shows Specimen 2 with its sensors at the end of the test. The results show that: 
- FOS2 and FOS6 behavior was excellent during the whole test. The maximum temperatures measured were $990{ }^{\circ} \mathrm{C}$ by FOS 2 and $957^{\circ} \mathrm{C}$ by FOS6 at $3600 \mathrm{~s}$, when the sensors differed by only $3.3 \%$ of the temperature as measured by FOS2. FOS4 stopped working after 3156 seconds, when it was recording temperatures of $940{ }^{\circ} \mathrm{C}$. Failure was due to explosive spalling breaking the packaging (Figure 9b) and leaving the RFBG exposed to the harsh test environment. FOS2 recorded a temperature of $948^{\circ} \mathrm{C}$ at $3156 \mathrm{~s}$, which differed from FOS2 by only $0.84 \%$.

- Again, some discrepancies in the measurements were found at the beginning of the test due to slight variations in the vertical position of the sensors and also to a burner at $50 \mathrm{~cm}$ over the specimen and not symmetrically aligned with it. Peaks and valleys also appear which can be attributed to the short response of the FOS, with FOS2 and TC2 showing the shortest response time.

- A fast temperature rise was registered by all the sensors after $600 \mathrm{~s}$, which can also be attributed to detachment of the sensor-adhesive set from the surface by spalling and the placement of the sensors in a final position which was outside the gas boundary layer.

- After 1070s, the temperatures measured by the FOS (especially FOS2) closely matched the temperatures measured by PT3 and the FOS behaved better than thermocouple TC2. At 1070s, TC2 registered a temperature increase of $100{ }^{\circ} \mathrm{C}$ and measured higher temperatures than FOS until 2630s, when the furnace temperature dropped due to internal pressure stabilization. The reason for the difference in the temperatures measured by TC2 can be seen in Fig. 9b, which shows Specimen 2 and the sensors after the test, with the adhesive detached and split in two. This left the thermocouple completely free to move and explains the variation in its measurements.

Finally, despite the conceptual difference between gas temperatures measured by FOSs/TCs and adiabatic temperatures measured by PTs, the values registered by all those sensors while FOSs and TCs were outside the gas boundary layer were similar. There are two reasons that explain the similarity of those measurements. First, the heat transfer process is dominated by radiation and the measurement of the sensors will be mainly affected by this part of the heat transfer process. As a consequence the difference of the measurements will not be affected significantly by the variation of the areas of the sensors which mainly affect the convective heat transfer. On the other hand, the radiation emitted by the concrete specimens is of minor importance compared with the radiation of the flames and the furnace walls, thus the measurements of FOSs and TCs that are affected by the radiation of the concrete specimen are in the same order of magnitude as the measurements of the PTs that are insulated of the radiation of the concrete specimen. On the other hand, temperatures registered by FOSs are higher than the specimen surface temperatures calculated by the FEM, corroborating the idea that the FOSs measure gas temperatures and not surface temperatures. As an example of the FEM results Figure 10 shows the temperature distribution on Specimen 1 at the end of the test.

\section{Conclusions}

This paper describes a set of proposed new fiber optic sensors based on RFBG technology for recording high temperatures for use in fire engineering as well as other fields such as power plants. The sensors were placed close to the surface of two concrete specimens and tested under the ISO 834 fire curve conditions for one hour. During the test the sensors measured temperatures of circa $970{ }^{\circ} \mathrm{C}$ and were directly subjected to flames and high temperature increments (in the order of $200^{\circ} \mathrm{C} / \mathrm{min}$ ), similar to those in actual fire situations. The results obtained by the sensors were in good agreement with those provided by thermocouples Moreover, the comparison of the FOS temperatures with the surface temperatures calculated by the numerical heat transfer models confirms that the sensors were not in contact with the specimens and that they did not measure their surface temperatures. The following additional conclusions can be drawn: 
(a) The gas temperatures provided by the sensors were affected by the distance between the sensors and the surface of the host element. To measure gas temperatures it is necessary to guarantee that the sensors are installed outside the gas boundary layer. The thickness of the boundary layer depends on several factors such as the gas velocity and was underestimated during the installation of the sensors. At the beginning of the test the sensors were approximately $2 \mathrm{~mm}$ apart from the surface of the specimens. After the detachment of the adhesive, the sensors increased their distance from the surface and consequently an increment on the temperatures measured was registered which clearly shows that the sensors were outside the boundary layer. This distance is therefore an important parameter to be considered in future practical applications.

(b) Special care should be taken when the temperatures on the surface of the host element and not gas temperatures are to be measured. In such cases the sensor should be completely in contact with the surface of the host element and action should be taken to prevent the detachment of the sensor from the host element. Applications on concrete surfaces are especially challenging due to spalling and are currently limited to cases where it can be reduced or avoided. In this regard, the connection between the sensors and the cable containing the optical fiber connecting the sensor to the data acquisition system is the critical component of the monitoring system. Additional research is required to define how this connection can be made resistant to spalling.

(c) Fiber optic sensors with packaging A showed the best behavior, as they were able to resist the harsh conditions of the fire test and also showed the shortest response time. Due to their fragility, sensors with packaging B should not be placed on the surface of concrete elements.

(d) Fiber optic high temperature sensors are competitive with thermocouples, especially in cases in which thermocouples would not be reliable due to the presence of electrical and/or magnetic interference, as in the case of the tunnels and bridges over electric railways.

Finally, we consider that this work is an important step forward over previous research in which sensors were tested in electric furnaces under very controlled conditions or fiber optic sensors were subjected to much lower temperatures. However, additional work is still required to implement a monitoring system in building structures under real fire scenarios, as individual applications need a detailed implementation study and testing.

\section{Acknowledgements}

This work has been possible thanks to the financial support of the Spanish Ministry of Science and Innovation (Research Projects BIA 2011-27104 and TEC2011-29120-C05-05). Funding for this research was provided to Paula Rinaudo by the European Commission (Erasmus Mundus Project Action 2 ARCOIRIS).

\section{References}

[1] Høj, N. P., Wageneder, J., Fellinger, J. H. H., Foit, W., Hejny, H., Breunese, A. J., Feron, C. (2003). Critical Structural and Functional Components. UPTUN. Workpackage 4 Fire Effects and Tunnel Performance: System Structural Response D411.

[2] Calavera, J., González-Valle, E., Díaz-Lozano, J., Fernández-Gomez, J., Ley, J., \& Izquierdo, J. (2005). Fire in the Windsor building, Madrid. Survey of the fire resistance and residual bearing capacity of the structure after the fire. Instituto Técnico de Materiales y Construcciones (INTEMAC). 
[3] G.Y. Wang, Y.Q. Li, C.H. Qiu, L.H. Han, H.X. Yu and F.D. Xie. Post-fire performance evaluation method of high-rise buildings and its application in the Television Cultural Center, CCTV. 8th International Conference on Structures in Fire SiF'14, Tongji University, Shanghai, China, 2014

[4] S. Brohez, C. Delvosalle, and G. Marlair, A two-thermocouples probe for radiation corrections of measured temperatures in compartment fires, Fire Saf. J, 39 (2004) 399-411.

[5] T. Mcallister, W. Luecke, M. Iadicola, and M. Bundy, Measurement of Temperature, Displacement, and Strain in Structural Components Subject to Fire Effects: Concepts and Candidate Approaches, NIST Technical Note 1768, 2012.

[6] V. M. Churikov, V. I. Kopp, and A. Z. Genack, Chiral diffraction gratings in twisted microstructured fibers., Opt. Lett. 35 (2010) 342-4.

[7] M. Busch, W. Ecke, I. Latka, and D. Fischer, Inscription and characterization of Bragg gratings in single-crystal sapphire optical fibres for high-temperature sensor applications, Meas. Sci. Technol. 20 (2009) 11530-11536.

[8] Y. Tu, Y.-H. Qi, and S.-T. Tu, Fabrication and thermal characteristics of multilayer metal-coated regenerated grating sensors for high-temperature sensing, Smart Mater. Struct. 22 (2013) 7502675036.

[9] A. Lönnermark, P. O. Hedekvist, and H. Ingason, Gas temperature measurements using fibre Bragg grating during fire experiments in a tunnel, Fire Saf. J. 43 (2008) 119-126.

[10] A. Bueno, B. Torres, D. Barrera, P. A. Calderón, M. Lloris, M. J. López, and S. Sales, Optical fiber sensors embedded in concrete for measurement of temperature in a real fire test, Opt. Eng., 50 (2011) 124404

[11] ISO (International Standards Organization), ISO 834- Fire resistance tests - Elements of building construction. Switzerland: International Standards Organisation, 1980.

[12] SIMULIA, Abaqus 6.13.

[13] K. T. V Grattan and B. T. Meggitt, Optical Fiber Sensor Technology., Chapman \& Hall, 1995.

[14] K. T. V Grattan and T. Sun, Optical Fiber Sensor Technology: Advanced Applications - Bragg Gratings and Distributed Sensors, Springer, 2000.

[15] T. Erdogan, V. Mizrahi, P. J. Lemaire, and D. Monroe, Decay of ultraviolet-induced fiber Bragg gratings, J. Appl. Phys. 76 (1994) 73.

[16] J. Canning, K. Sommer, and M. Englund, Fibre gratings for high temperature sensor applications, Meas. Sci. Technol. 12 (2001) 824-828.

[17] J. Canning, M. Stevenson, K. Cook, M. Aslund, W. Ecke, R. Willsch, H. Bartelt, H. J. Kalinowski, L. Grabarski, V. Oliveira, C. Martelli, a. Braga, N. Groothoff, and G.-D. Peng, Optical fibre Bragg gratings for high temperature sensing, 7503 (2009) 75032N-75036N.

[18] D. Barrera, V. Finazzi, G. Coviello, A. Bueno, S. Sales, V. Pruneri, and C. De, Wavelength encoded fiber sensor for extreme temperature range, Proc. SPIE 7653, Fourth European Workshop on Optical Fibre Sensors (2010) 76530E.

[19] P. Rinaudo, B.Torres, D. Barrera, P. Calderón, I. Payá-Zaforteza, S. Sales, Sensores de alta temperatura para la monitorizacion de Estructuras ante la acción del fuego.High temperature sensors for monitoring structures under fire load. VI CONGRESO DE ACHE, Madrid, Spain (2014) [in Spanish].

[20] U. Wickström, D. Duthinh, K. McGrattan, Adiabatic surface temperature for calculating heat transfer to fire exposed structures,Proceedings of the Eleventh International Interflam Conference. Interscience Communications, 167(2007)

[21] Micron Optics, Sensing analysis software ENLIGHT. [Online]. Available: http://www.micronoptics.com/uploads/library/documents/datasheets/Micron_Optics_ENLIGHT.pd f. [Accessed: 04-Apr-2014].

[22] CEN, Eurocode 2: Design of concrete structures - Part 1-1: General rules and rules for buildings. Brussels, Belgium: Comité Européen de Normalisation, 2004.

[23] CEN, Eurocode 1: Actions on structures. Part 1-2: General actions - Actions on structures exposed to fire. Brussels, Belgium: Comité Européen de Normalisation, 2002. 


\begin{tabular}{|c|c|c|c|}
\hline & Specimen & Packaging & $\lambda_{0}(\mathrm{~nm})$ \\
\hline FOS1 & 1 & A & 1543.520 \\
\hline FOS2 & 2 & A & 1557.255 \\
\hline FOS3 & 1 & B & 1459.610 \\
\hline FOS4 & 2 & B & 1529.825 \\
\hline FOS5 & 1 & C & 1530.095 \\
\hline FOS6 & 2 & C & 1553.340 \\
\hline
\end{tabular}

Table 1 Location and main features of the fiber optic sensors tested. 


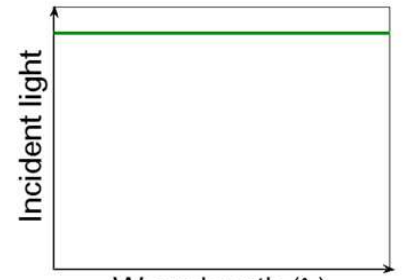

Wawelength $(\lambda)$

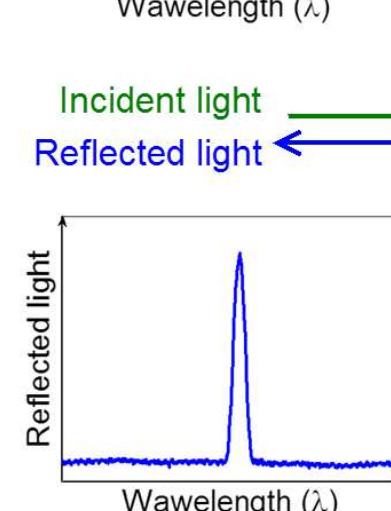

Figure 1: Response to an incident light (green arrow) of a uniform Fiber Bragg Grating with period $\Lambda$. Reflected light (blue arrow) and transmitted light (purple arrow).

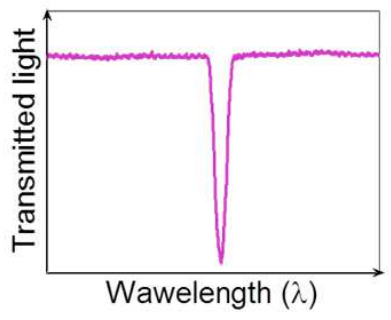

Transmitted light

\section{Period $(\Lambda)$}

Fiber core

Grating length 

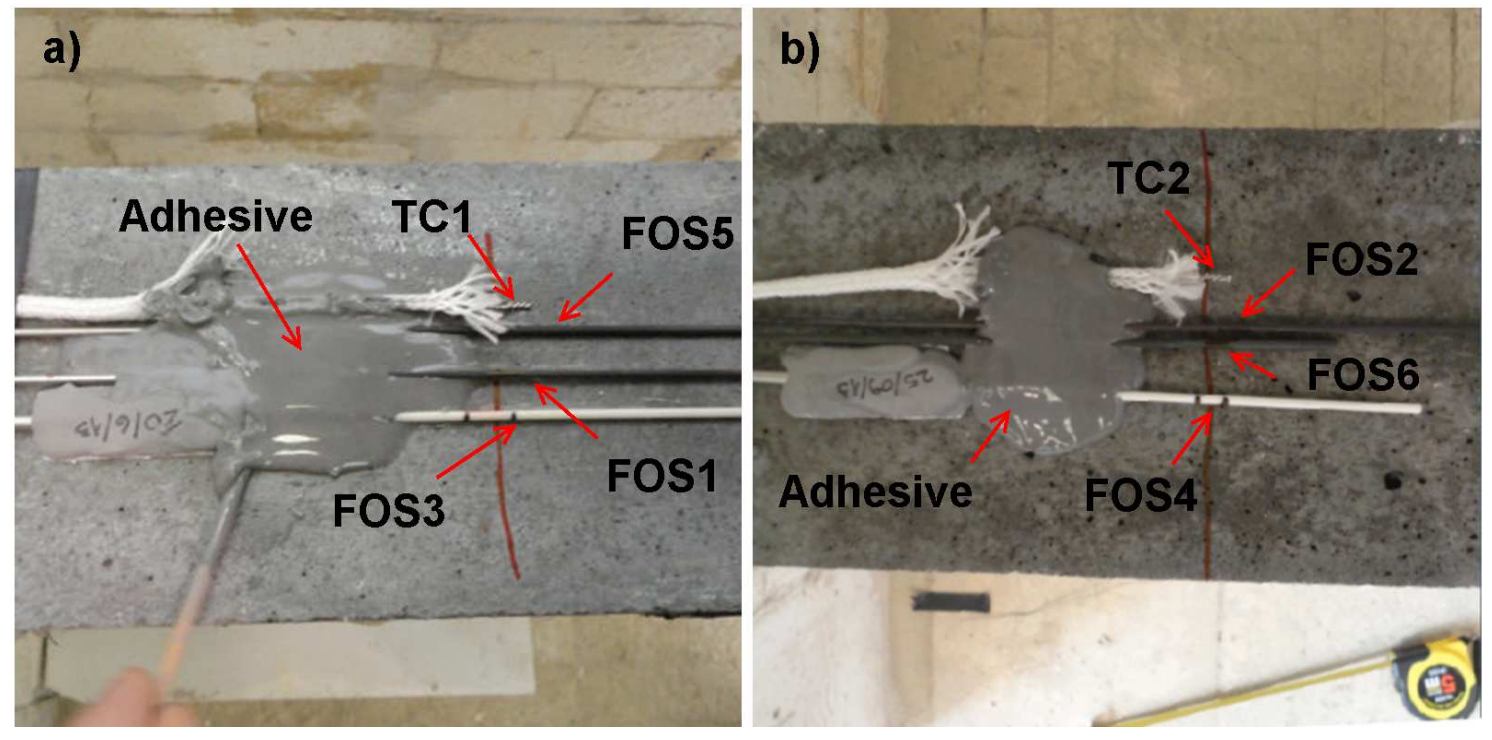

Figure 2. Sensor layout: a) Sensors on Specimen 1: Thermocouple TC1 and fiber optic temperature sensors FOS1, FOS3 and FOS5; b) Sensors on Specimen 2: Thermocouple TC2 and fiber optic temperature sensors FOS2, FOS4 and FOS6. 


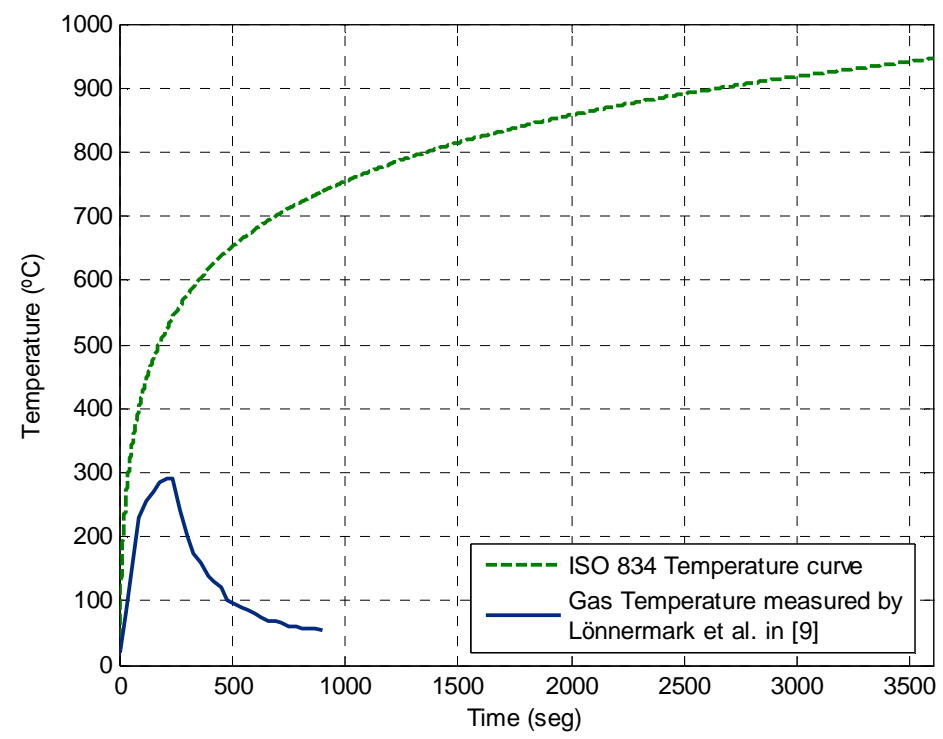

Figure 3. Comparison of the ISO 834 fire curve applied in the present study and fire curve applied by Lönnermark et al. [9]. 


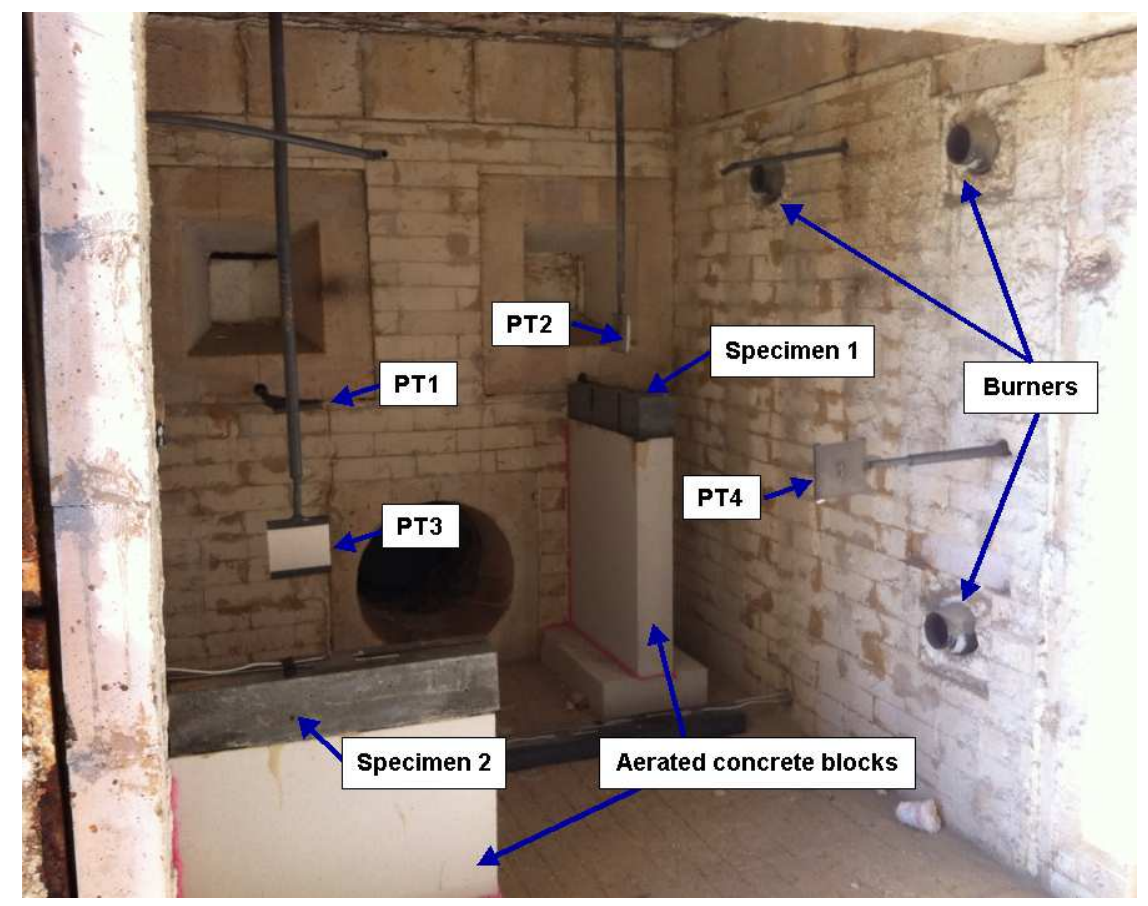

Figure 4. Furnace front view. Position of the burners on the right wall of the furnace, plate thermometers (PT1 to PT4), aerated concrete blocks and concrete specimen (Specimens 1 and 2). 

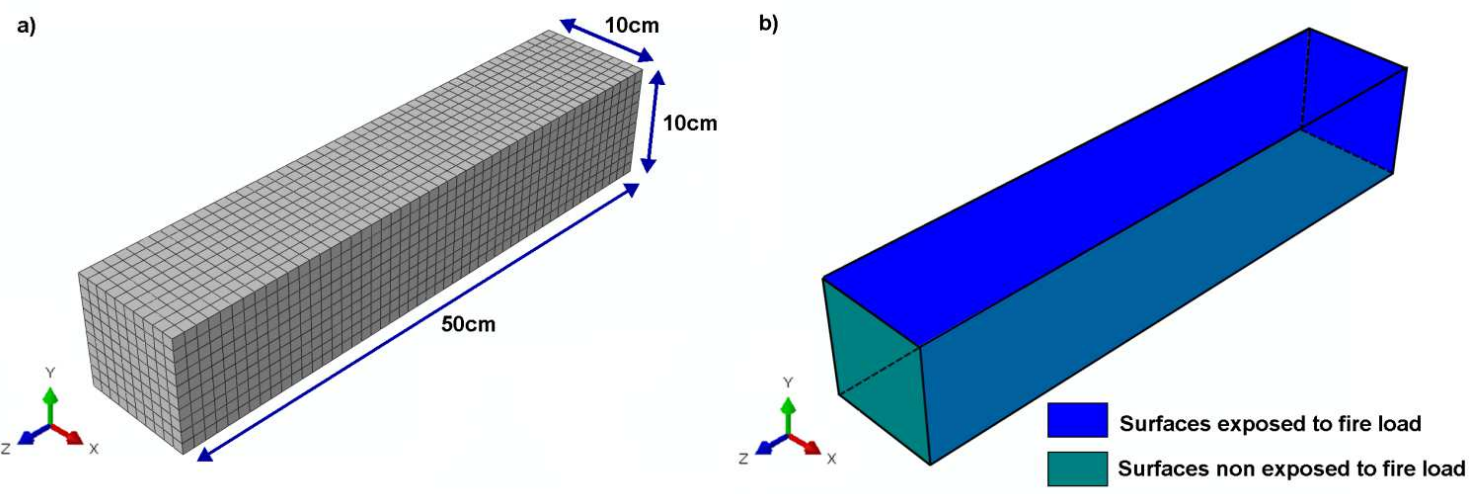

Figure 5: General view of the heat transfer model: a) Dimensions of the model and the mesh. b) Surfaces exposed and non-exposed to fire load. 


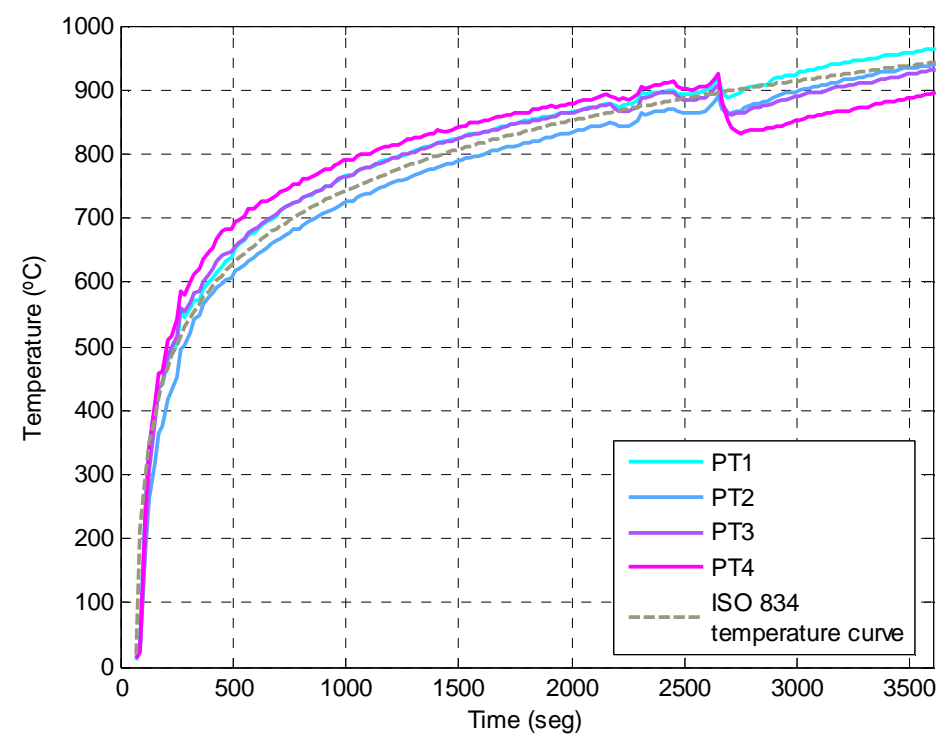

Figure 6: Temperature inside the furnace measured by the plate thermometers and theoretical ISO 834 fire curve 

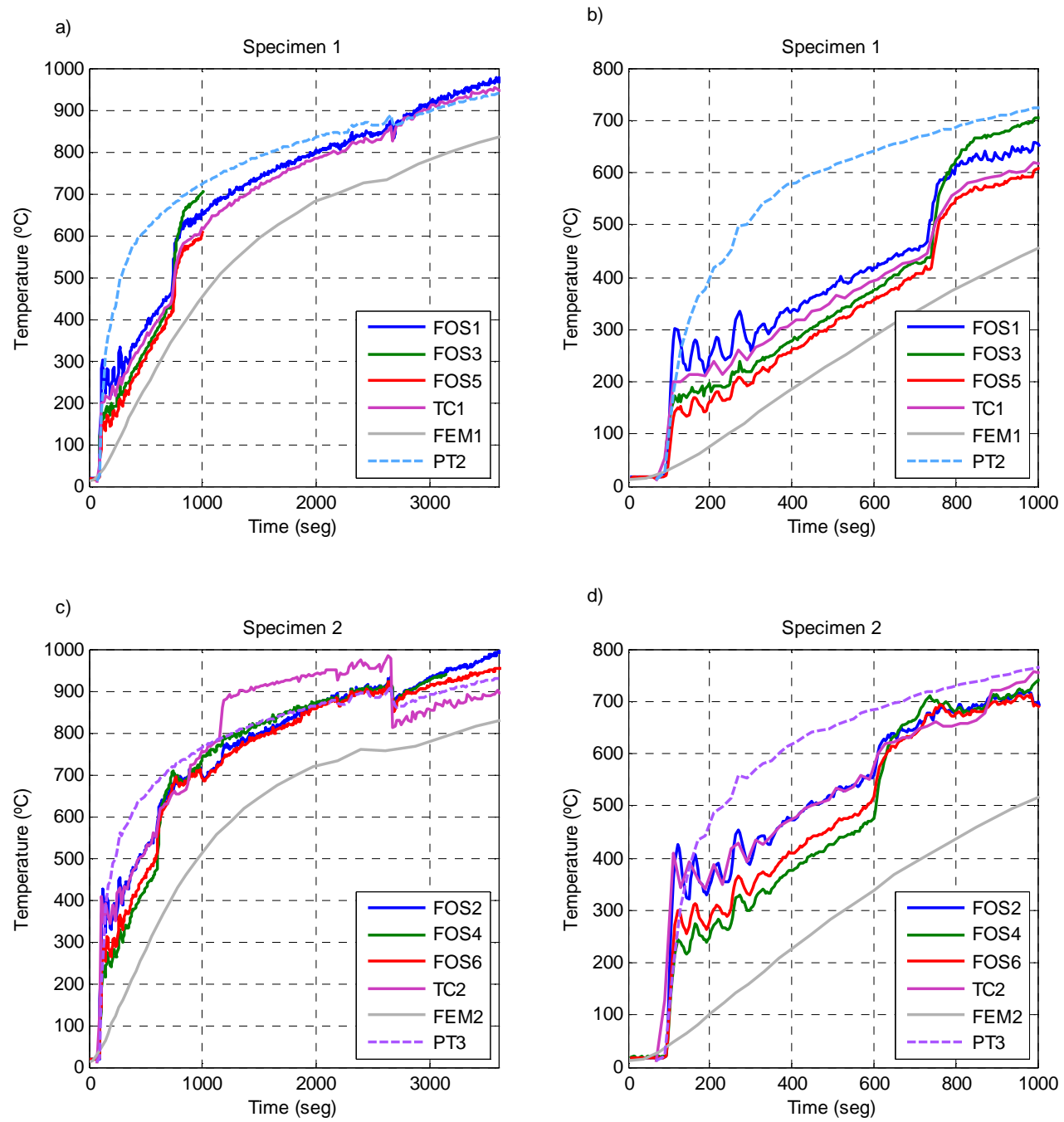

Figure 7: Time-Temperature curves. Temperature measurements given by fiber optic sensors (FOS), thermocouples (TC) and plate thermometers (PT). Theoretical surface temperatures from FEMs are also plotted. a) Specimen 1, b) Specimen1 zoom, c) Specimen 2, d) Specimen 2 zoom. 

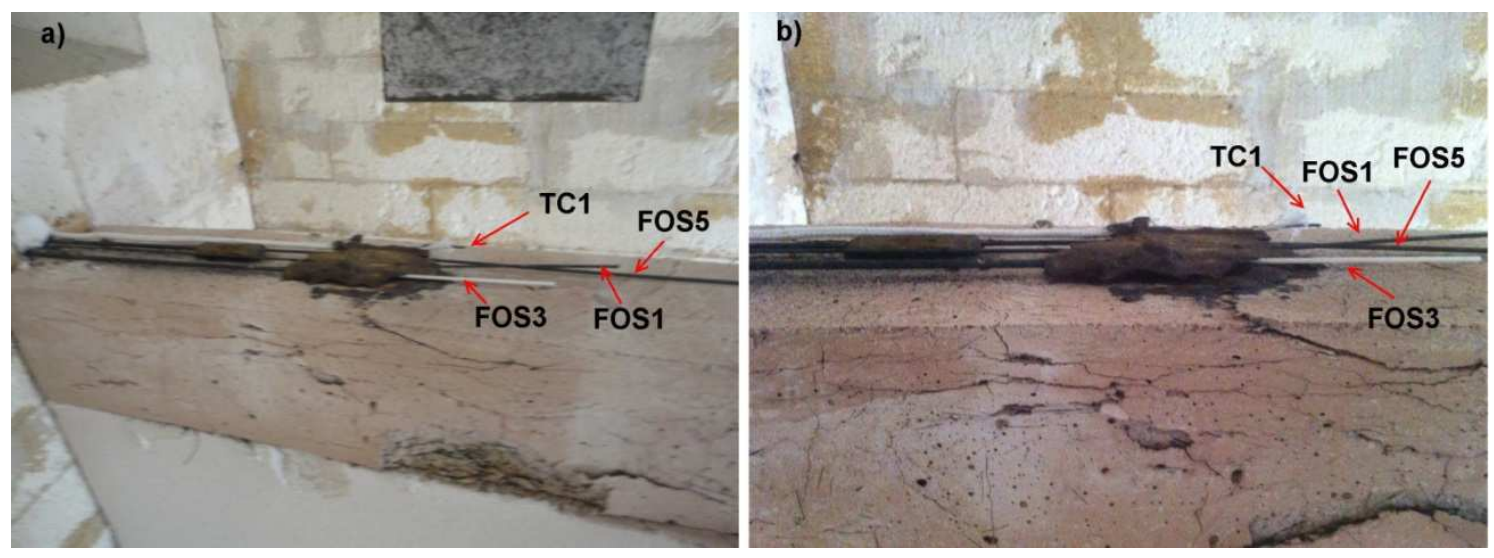

Figure 8: Specimen 1 after the test. a) Final position of the sensors, general view. b) Spalling near the joint between the sensors and the fiber optic cable, lateral view. 

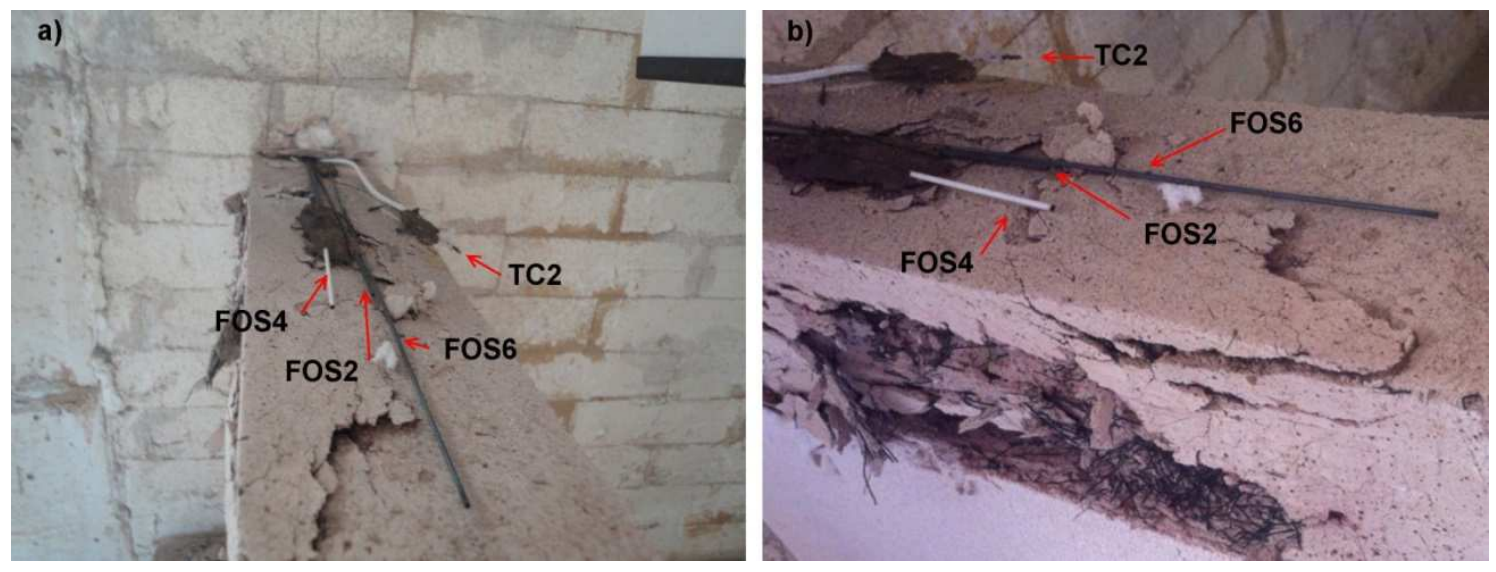

Figure 9: Specimen 2 after the test. a) Final position of the sensors, upper view, b) Spalling and concrete detachment near FOS4 


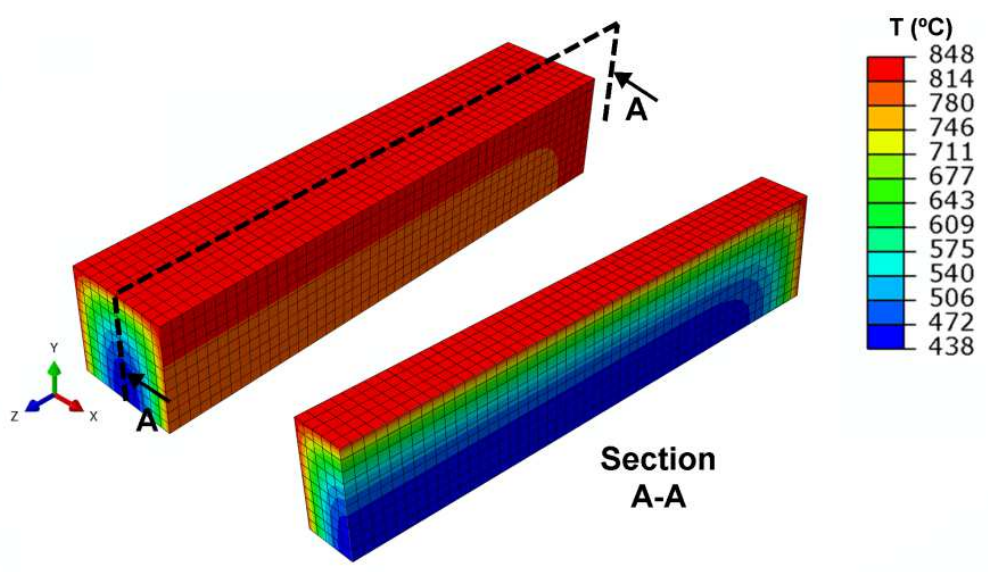

Figure 10: Temperatures in Specimen 1 at the end of the fire test (after 3600 seconds) given by the heat transfer FEM. The results in Specimen 2 are very similar. 